\title{
It is not time to lower the guard!
}

\author{
Isabella Annesi-Maesano1,2
}

Affiliations: ${ }^{1}$ Epidemiology of Allergic and Respiratory Diseases (EPAR), INSERM, UMR-S 1136, IPLESP, Paris, France. ${ }^{2}$ Epidemiology of Allergic and Respiratory Diseases (EPAR), UPMC, UMR-S 1136, IPLESP, Paris, France.

Correspondence: Isabella Annesi-Maesano, Epidemiology of Allergic and Respiratory Diseases Dept, INSERM and UPMC, UMR-S 1136, Institute Pierre Louis of Epidemiology and Public Health, Epidemiology of Allergic and Respiratory Diseases, Medical School Saint-Antoine, 27, rue Chaligny, Paris 75571, CEDEX 12, France. E-mail: isabella.annesi-maesanodinserm.fr

0 @ERSpublications

Answers to questions on health effects of air pollution will require funding at European and international levels http://ow.ly/HMkvX

\begin{abstract}
A few days ago, I was interviewed by a group of masters students who, as part of their training, needed to know whether and how it is possible to establish a causal role of air pollution in the inception of asthma. They already knew that air pollution can exacerbate asthma in patients who already suffer from the condition. I gave them the usual didactic reply: it is necessary to verify Hill's criteria to prove causality between an exposure and the development of a disease. In the case of air pollution and asthma development, several of these criteria are verified. Among the most important is the statistically significant association between the two, as assessed by the computation of the associated risk (usually relative risks or odds ratios), the temporal sequence (prospective studies indicate that exposure precedes the disease), confirmation by toxicological and experimental studies that provide insights on underlying mechanisms, and biological plausibility.
\end{abstract}

The existence of a causal link between air pollution and asthma development is supported by epidemiological evidence. First, several longitudinal population studies have separately shown positive associations of early-life exposure to air pollution with asthma [1,2]. Successively, a meta-analysis of birth-cohort data found an association between asthma incidence and within-community variations in air pollution in large, traffic-dominated urban settings [3]. Similarly, a systematic review suggested an association of asthma prevalence with exposure to traffic, although only in those living very close to heavily trafficked roads carrying several lorries [4]. Other studies, however, did not find any association, which could be due to differences in study design in terms of case definition and exposure assessment, populations, and periods of survey [5,6]. Overall, our colleagues in the UK suggested that the evidence is consistent with the possibility that outdoor air pollution might play a role in causing asthma in susceptible individuals living very close to busy roads carrying heavy lorry traffic [7], which is supported by increasing evidence in Europe and elsewhere. Notably, the observed odds ratios were not elevated (unlike the risk of lung cancer from smoking tobacco, for example), which can be explained by the fact that asthma is a multifactorial disease and is dependent on the simultaneous occurrence of several exposures to both genetic and environmental factors [8]. Air pollution is one of the many factors related to asthma. The peculiarity of this factor that renders it dangerous is that it is ubiquitous and, in many parts of the world, increasing.

An article in this issue of the European Respiratory Journal (ERJ) by MöLTER et al. [9] seems to challenge the impact of air pollution on asthma and wheeze. In the context of the European Study of Cohorts for Air Pollution Effects (ESCAPE), using data on asthma and wheezing from five European birth cohorts and six traffic-related air pollution metrics (nitrogen dioxide, nitrogen oxides, particulate matter with an aerodynamic diameter $<10 \mu \mathrm{m}$ (PM10), PM2.5, coarse particulate matter and PM2.5 absorbance) at the birth address of the participants, these authors did not find any significant association between air pollution

Received: Jan 192015 | Accepted: Jan 192015

Conflict of interest: None declared.

Copyright OERS 2015 
exposure at birth and childhood asthma prevalence. The absence of a relationship between asthma prevalence and air pollution is not new [10] and some hypotheses can be raised in this respect. A major concern in the study by MöLter et al.[9] results from exposure misclassification. Air pollution assessments were performed at the home address of each child at birth during the ESCAPE study, i.e. several years after birth. Land-use regression models were specifically developed for the ESCAPE protocol and covered three 2-week-long measurements at 40 sites in 2009. They were then applied retrospectively to the stages of life considered in the analyses, namely, birth, age 4 or 5 years, and age 8 or 10 years, through back-extrapolation over time and relative comparison with the urban routine monitoring background station values of each stage of life. Although this approach was published [11], it is not clear whether it considers real changes in air pollution over past decades at the small scale: for example, not only have urban air pollution emissions decreased since the 1990s when the birth cohort study began, but the composition of particular matter, and thus its dangerousness, could have changed over time as well. In addition, the importance of making individual assessments has been demonstrated [12]. Exposure misclassification could also be due to the lack of information on indoor air pollution exposure of the children at home and school [13], as well as inside vehicles when commuting, which are also well-known risk factors for asthma. These factors vary in a significant way between birth and later childhood. Exposure misclassification could explain why, for example, in the study by Mölter et al. [9], the adjusted odds ratios for asthma at age 8-10 years and exposure at the birth address were $>1$ (including 1.10 for $\mathrm{NO}_{2}$ and 1.23 for $\mathrm{PM} 2.5$, where a value of 1.10 indicates a $10 \%$ higher risk and a value of 1.23 a $23 \%$ higher risk, respectively), but not significant, which could also be due to a lack of statistical power. Because of Hill's criteria, findings on asthma incidence have to be considered more robust than those on asthma prevalence to establish causality. Overall, various significant or almost-significant associations, like in the ESCAPE study, have been found for both asthma incidence and prevalence, which tie up air pollution to asthma development.

Above all, the authors of the study and the ESCAPE community have to receive an encomium for the important work done so far [14]. For the first time, using a standardised methodology and refined exposure assessment tools, the study investigated and established long-term effects on human health from exposure to air pollution in Europe. This was crucial in a context where available estimates were primarily based on exposure-response relationships established in studies from North America.

The article by MöLter et al. [9] ends by indicating that it could also be important to consider European conurbations that might have experienced higher pollutant concentrations and that were never considered previously. The inclusion of genetic data in further analyses may provide useful insights into potential gene-environment interactions between air pollution and asthma. The existing literature indicates that other important research questions are still open, including the following. 1) How should we assess air pollution exposure and particulate matter composition in order to avoid exposure misclassification of individuals? 2) At what distance from roads or traffic emission sources would the exposure to vehicular emissions be diminished to safe levels? Indeed, there is no consensus regarding exposure thresholds. 3) What volume of car and lorry traffic is tolerable? 4) Should we advise patients with asthma to avoid prolonged exposure in close proximity to roads? If so, how much time constitutes prolonged exposure? What distance is far away enough? 5) Should an asthmatic be advised not to reside or attend school or work based on the potential for nearby traffic exposure?

In a recent editorial titled "Clean air in Europe: beyond the horizon?", the Environmental and Health Committee of the European Respiratory Society, of which I am a member, warned about the fact that we still have to worry about air pollution in Europe and that adverse health effects of air pollution are now being observed at ever-lower concentrations of air pollutants [15]. Based on such evidence, the

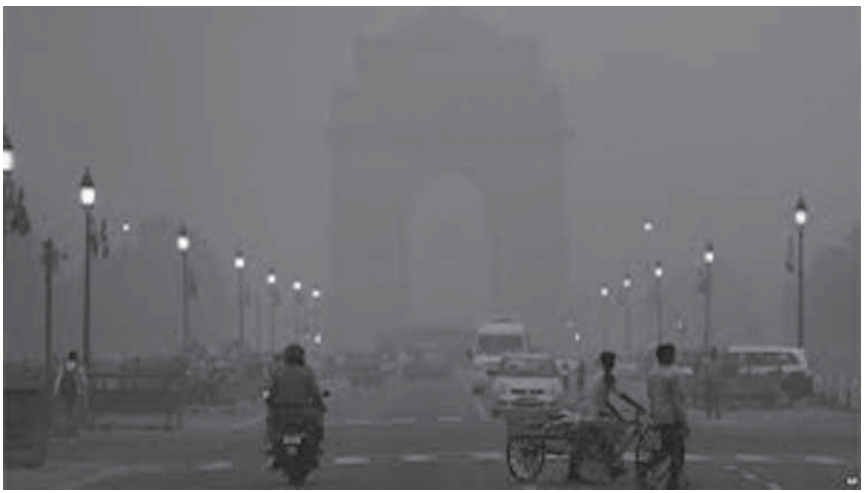

FIGURE 1 Lights during daytime in Delhi, India, covered by haze mainly caused by air pollution. 
authoritative Global Burden of Disease reports, published in late 2012, document that in Europe, PM2.5 in the air is clearly the most important environmental health concern among the major drivers of ill health and premature mortality in the population. This message has been reinforced in another editorial published by the ERJ entitled "ESCAPEing from bad-quality air: a cleaner air, from Europe to elsewhere", where the globalisation of air pollution was taken into account [16]. I have just returned from New Delhi (India) where levels of air pollution are far beyond World Health Organization (WHO) and European standards (PM2.5 concentration at $410 \mu \mathrm{g} \cdot \mathrm{m}^{-3}$ on Monday, January 19, 2015, when the WHO level is $25 \mu \mathrm{g} \cdot \mathrm{m}^{-3}$ ), thus strongly threatening its inhabitants' lives. Studies on air pollution and mortality from New Delhi found that all-natural-cause mortality and morbidity increased with increased air pollution [17]. This is only one of the many conurbations where outdoor air pollution is rapidly increasing in the world (fig. 1). So far, the health impact of elevated doses and prolonged exposure has still to be assessed.

The answers to all the existing questions on the health effects of air pollution will come from further large, collaborative investigations that require funding by ad hoc programmes at the European and international levels. These answers are crucial in terms of clinical implications for the care of asthmatics and other patients, as well as for public health policies, and urban planning and development in Europe and elsewhere.

\section{References}

1 Gauderman WJ, Avol E, Lurmann F, et al. Childhood asthma and exposure to traffic and nitrogen dioxide. Epidemiology 2005; 16: 737-743.

2 Gruzieva O, Bergstrom A, Hulchiy O, et al. Exposure to air pollution from traffic and childhood asthma until 12 years of age. Epidemiology 2013; 24: 54-61.

3 Dore CJ, Murrells TP, Passant NR, et al. UK Emissions of Air Pollutants 1970 to 2006. http://uk-air.defra.gov.uk/ assets/documents/reports/cat07/0810291043_NAEI_2006_Report_Final_Version\%283\%29.pdf Date last accessed: June 12, 2012. Date last updated: October 2008.

4 Committee on the Medical Effects of Air Pollutants. Statement and working papers on the question 'Does outdoor air pollution cause asthma?'. 25 Nov 2010. http://webarchive.nationalarchives.gov.uk/20100505104658/ http://www. comeap.org.uk/documents/statements/39-page/linking/53-does-outdoor-air-pollution-cause-asthma Date last accessed: June 12, 2012.

5 Kramer U, Sugiri D, Ranft U, et al. Eczema, respiratory allergies, and traffic-related air pollution in birth cohorts from small-town areas. J Dermatol Sci 2009; 56: 99-105.

6 Mölter A, Agius R, de Vocht $\mathrm{F}$, et al. Effects of long-term exposure to $\mathrm{PM}_{10}$ and $\mathrm{NO}_{2}$ on asthma and wheeze in a prospective birth cohort. J Epidemiol Community Health 2014; 68: 21-28.

7 Gowers AM, Cullinan P, Ayres JG, et al. Does outdoor air pollution induce new cases of asthma? Biological plausibility and evidence; a review. Respirology 2012; 17: 887-898.

8 Becklake MR, Ernst P. Environmental factors. Lancet 1997; 350: Suppl. 2, SII10-SII13.

9 Mölter A, Simpson A, Berdel D, et al. A multicentre study of air pollution exposure and childhood asthma prevalence: the ESCAPE project. Eur Respir J 2015; 45: 610-624.

10 Anderson HR, Favarato G, Atkinson RW. Long-term exposure to air pollution and the incidence of asthma: meta-analysis of cohort studies. Air Qual Atmos Health 2013; 6: 47-56.

11 Beelen R, Stafoggia M, Raaschou-Nielsen O, et al. Long-term exposure to air pollution and cardiovascular mortality: an analysis of 22 European cohorts. Epidemiology 2014; 25: 368-378.

12 Batterman S, Burke J, Isakov V, et al. A comparison of exposure metrics for traffic-related air pollutants: application to epidemiology studies in Detroit, Michigan. Int J Environ Res Public Health 2014; 11: 9553-9577.

13 Hulin M, Simoni M, Viegi G, et al. Respiratory health and indoor air pollutants based on quantitative exposure assessments. Eur Respir J 2012; 40: 1033-1045.

14 European Study of Cohorts for Air Pollution Effects. Published/accepted ESCAPE papers. www.escapeproject.eu/ publications.php Date last accessed: August 12, 2014. Date last updated: August 25, 2014.

15 Brunekreef B, Künzli N, Pekkanen J, et al. Clean air in Europe: beyond the horizon? Eur Respir J 2015; 45: 7-10.

16 Soriano JB, Powell P, Sealy S. ESCAPEing from bad-quality air: a cleaner air, from Europe to elsewhere. Eur Respir J 2015; 45: 11-13.

17 Rizwan S, Nongkynrih B, Gupta SK. Air pollution in Delhi: its magnitude and effects on health. Ind J Community Med 2013; 38: 4-8. 